\title{
Correction to: Usefulness of echocardiography for predicting ventricular tachycardia detected by implantable loop recorder in syncope patients
}

\author{
Mathilde Musoni Falsing ${ }^{1}$ (D) Philip Brainin ${ }^{1,2}$. Ditte Madsen Andersen ${ }^{1} \cdot$ Charlotte Ellen Larroudé ${ }^{1}$ \\ Tommi Bo Lindhardt ${ }^{1}$. Daniel Modin ${ }^{1}$. Kirstine Ravnkilde ${ }^{1}$. Emil Høegholm Karsum ${ }^{1}$. Gunnar Gislason ${ }^{1}$. \\ Tor Biering-Sørensen ${ }^{1,3}$
}

Published online: 2 July 2021

(c) Springer Nature B.V. 2021

\section{Correction to: \\ The International Journal of Cardiovascular Imaging \\ https://doi.org/10.1007/s10554-021-02295-z}

In the original publication of the article the second and the fifth author name was incorrect. These errors have been corrected in the revised version.

The original article has been corrected.

Publisher's Note Springer Nature remains neutral with regard to jurisdictional claims in published maps and institutional affiliations.

The original article can be found online at https://doi.org/10.1007/ s10554-021-02295-z.

Mathilde Musoni Falsing

Mathilde_falsing@hotmail.com

1 Cardiovascular Non-Invasive Imaging Research Laboratory, Department of Cardiology, Herlev \& Gentofte Hospital, University of Copenhagen, Niels Andersens Vej 65, Post 835, 2900 Hellerup, Denmark

2 Department of Cardiology, Federal University of Acre, Rio Branco, Acre, Brazil

3 Department of Biomedical Sciences, Faculty of Health and Medical Sciences, University of Copenhagen,

Copenhagen, Denmark 